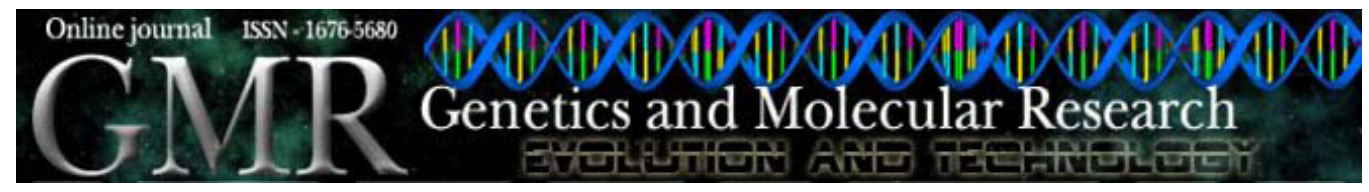

\title{
Population genetic structure of the blue-fronted Amazon (Amazona aestiva, Psittacidae: Aves) based on nuclear microsatellite loci: implications for conservation
}

\author{
K.C.E. Leite ${ }^{1}$, G.H.F. Seixas ${ }^{2}$, I. Berkunsky ${ }^{3}$, R.G. Collevatti ${ }^{1}$ \\ and R. Caparroz ${ }^{1}$ \\ ${ }^{1}$ Pós-graduação em Ciências Genômicas e Biotecnologia, \\ Universidade Católica de Brasília, Brasília, DF, Brasil \\ ${ }^{2}$ Projeto Papagaio-Verdadeiro, Fundação Neotrópica do Brasil, Bonito, MS, Brasil \\ ${ }^{3}$ Facultad de Ciencias Exactas y Naturales, \\ Universidad de Buenos Aires, Buenos Aires, Argentina \\ Corresponding author: R. Caparroz \\ E-mail: renatocz@yahoo.com.br
}

Genet. Mol. Res. 7 (3): 819-829 (2008)

Received June 17, 2008

Accepted July 2, 2008

Published September 9, 2008

\begin{abstract}
The blue-fronted Amazon (Amazona aestiva) is a widely distributed Neotropical parrot and one of the most captured parrots in nature to supply the illegal trade of wild animals. The objectives of the present study were to analyze the genetic structure of A. aestiva to identify management units and support conservation planning and to verified if $A$. aestiva populations have undergone a recent bottleneck due to habitat loss and capture for the pet trade. The genetic structure was accessed by analyzing six microsatellite loci in 74 individuals of $A$. aestiva, including samples from the two subspecies (A. a. aestiva and $A$. a. xanthopteryx), from five populations: four in Brazil and one in Argentina. A significant genetic dif-
\end{abstract}


ferentiation $(\theta=0.007, \mathrm{P}=0.005)$ could be detected only between the most distant populations, Tocantins and Argentina, localized at the northeast and southwest limits of the sample sites, respectively. There was no evidence of inbreeding within or between populations, suggesting random mating among individuals. These results suggest a clinal distribution of genetic variability, as observed for variation in plumage color of the two A. aestiva subspecies. Bottleneck analysis did not show a recent reduction in population size. Thus, for the management and conservation of the species, the populations from Argentina and Tocantins should be considered as different management units, and the other populations from the center of the geographical distribution as another management unit.

Key words: Amazona aestiva; Microsatellite; Genetic structure; Bottleneck; Conservation

\section{INTRODUCTION}

Habitat fragmentation may reduce population size and modify dispersal and population geographic distribution, affecting ecological and genetic processes in remaining populations (Gilpin and Soulé, 1986). Small and isolated populations may become extinct by demographic or environmental stochastic fluctuations or by natural catastrophes, and still may show a genetic decline in response to processes such as inbreeding depression and genetic drift (Franklin, 1980; Gilpin and Soulé, 1986; Frankham, 1995). Additionally, restricted gene flow among fragmented populations may lead to genetic differentiation, reinforcing the effects of genetic drift and inbreeding (Soulé, 1987; Gilpin, 1987; Frankham et al., 2002). Besides, population fragmentation due to habitat loss and landscape modification may reinforce the isolation-by-distance process (Wright, 1943) due to long-distance gene flow constraint.

Throughout the last three decades, the identification of genetically distinct populations has been a key issue in conservation biology (Wayne, 1992; Paetkau, 1999; Frankham et al., 2002). Ryder (1986) and Moritz (1994) distinguished two types of conservation units, namely evolutionary significant unit and management unit. An evolutionary significant unit is defined as a population that is substantially reproductively isolated from other groups and that represents an important component in the evolutionary process of a species, whereas a management unit is a population with significant allelic divergence at nuclear or mitochondrial loci between populations. The relevance of these concepts and the genetic information in species conservation, including data on population structure, has been intensively recognized to develop and apply adequate conservation and management strategies (Paetkau et al., 1999; Eizirik et al., 2001; Coulon et al., 2006; Dethmers et al., 2006).

The blue-fronted Amazon (Amazona aestiva) is a widely distributed Neotropical parrot occurring from Northeast Brazil to Argentina (Collar, 1997). Two subspecies are recognized, based mainly on shoulder color and geographic distribution. A. a. aestiva has a red shoulder and is distributed in the Northeast and Central-East of Brazil, while $A$. $a$. 
xanthopteryx has a yellow shoulder and is distributed in the Southwest of Brazil, Bolivia, Paraguay, and Argentina. In the Brazilian States of Mato Grosso and Mato Grosso do Sul, an intermediate phenotype with mixed red and yellow shoulder can also be found (Darrieu, 1983). However, phylogenetic studies have shown evidence that this species comprises a paraphyletic group with A. ochrocephala complex (Eberhard and Bermingham, 2004; Russello and Amato, 2004; Ribas et al., 2007).

Habitat destruction due to agricultural and urban landscape expansion has been the main threat to A. aestiva, reducing natural cavities for nesting and food availability (Collar and Juniper, 1992). Furthermore, this species is the most frequently captured parrot in the world for the pet trade because of its exuberant color pattern, sociability and ability to reproduce human words. These two processes have contributed to a decrease in population size in the last decades, especially in some more disturbed and fragmented regions (Beissinger and Bucher, 1992). Despite that, only a few reports about the biology and ecology of A. aestiva are available and are restricted to studies performed in Argentina (Fernandez-Juricic et al., 1998; Banchs and Moschione, 2006) and in the Pantanal, Brazil (Seixas and Mourão, 2000, 2002, 2003). Genetic studies are almost exclusively about the phylogenetic relationship of A. aestiva and other related species (Eberhard and Bermingham, 2004; Russello and Amato, 2004; Ribas et al., 2007).

Considering the high pressure on the blue-fronted Amazon from illegal capture and the scarcity of population genetic studies, we are interested in generating useful information for A. aestiva conservation efforts. In the present study, we report on the population genetic structure of A. aestiva based on six microsatellite loci and on a bottleneck analysis to test the hypothesis that populations suffered a recent reduction in size. The consequences for conservation are also discussed.

\section{MATERIAL AND METHODS}

\section{Samples and genetic analysis}

Throughout 2001 to 2006, we collected blood samples from 74 nestlings from four localities in Brazil and one in Argentina (Table 1, Figure 1). Total genomic DNA was extracted using standard proteinase K/SDS digestion followed by phenol:chloroform:isoamyl alcohol purification as described by Bruford et al. (1992).

\begin{tabular}{|c|c|c|c|c|}
\hline Locality/State & Code & Geographic coordinates & $\mathrm{N}$ & Year* \\
\hline \multicolumn{5}{|l|}{ Brazil } \\
\hline Gurupi/Tocantins & TO & $11^{\circ} 43^{\prime} 44^{\prime \prime} \mathrm{S}, 49^{\circ} 04^{\prime} 08^{\prime \prime} \mathrm{W}$ & 15 & 2006 \\
\hline Brasília/Distrito Federal & DF & $14^{\circ} 47^{\prime} 03^{\prime \prime} \mathrm{S}, 47^{\circ} 55^{\prime} 25^{\prime \prime} \mathrm{W}$ & 11 & 2004/2005/2006 \\
\hline Chapada Gaúcha/Minas Gerais & MG & $15^{\circ} 17^{\prime} 06^{\prime \prime} \mathrm{S}, 46^{\circ} 03^{\prime} 33^{\prime \prime} \mathrm{W}$ & 10 & 2001 \\
\hline Pantanal Sul Mato-grossense/Mato Grosso do Sul & MS & $20^{\circ} 15^{\prime} 24^{\prime \prime} \mathrm{S}, 56^{\circ} 21^{\prime} 21^{\prime \prime} \mathrm{W}$ & 24 & $2001 / 2002 / 2004 / 2005$ \\
\hline \multicolumn{5}{|l|}{ Argentina } \\
\hline Província del Chaco & AR & $28^{\circ} 04^{\prime} 28^{\prime \prime} \mathrm{S}, 59^{\circ} 13^{\prime} 48^{\prime \prime} \mathrm{W}$ & 14 & 2004 \\
\hline
\end{tabular}

$\mathrm{N}=$ number of individuals. $*$ Refer to the breeding season when blood samples were collected. 


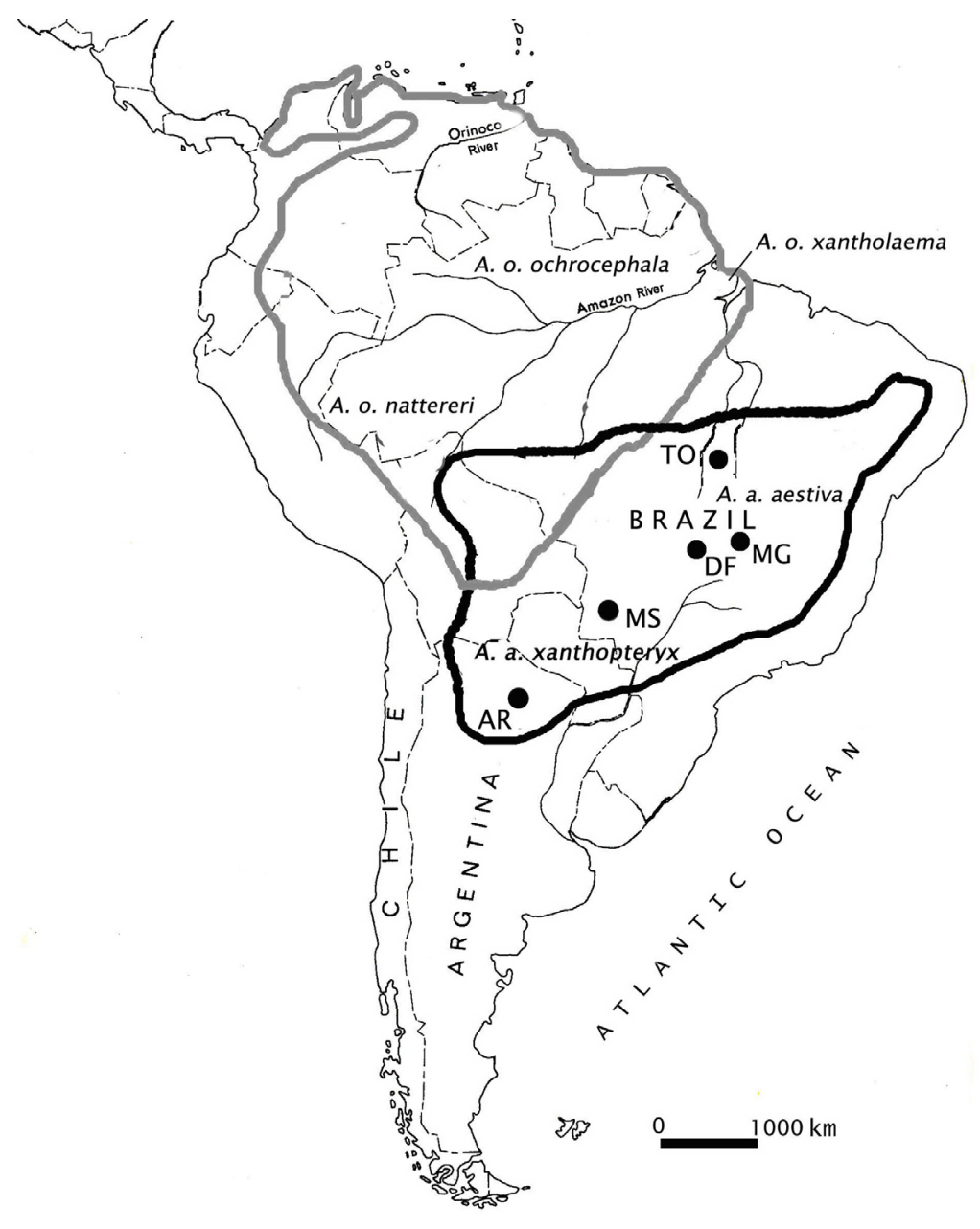

Figure 1. Geographic distribution of Amazona aestiva subspecies (black line) and of some A. ochrocephala subspecies (grey line). Black circles indicate sampling localities (see Table 1 for locality codes).

Six microsatellite loci (AgGT07, AgGT12, AgGT21, AgGT29, AgGT72, and AgGT83) described by Russello et al. (2001, 2005), and previously optimized for A. aestiva (Caparroz et al., 2007) were used to genotype all individuals. Although nine loci amplified for A. aestiva, the loci UnaCT43 and AgGT22 were excluded from the analysis because of deviation from Hardy-Weinberg equilibrium. Additionally, comparative analyses of population genetic structure including these loci indicated significant changes in the results that may not be explained by geographic distribution of populations. The locus AgGT90 was in linkage disequilibrium with AgGT07, and hence the locus AgGT90 was excluded from analysis (see Caparroz et al., 2007).

Forward primers were labeled with a fluorescent dye, 6-FAM, HEX or NED. The reactions were performed separately for each locus in a $10-\mu \mathrm{L}$ volume, containing $0.5 \mu \mathrm{M}$ of each 
primer, 1 unit Taq DNA Polymerase (Phoneutria, Brazil), $200 \mu \mathrm{M}$ of each dNTP, 1X reaction buffer $\left(10 \mathrm{mM}\right.$ Tris- $\left.\mathrm{HCl}, \mathrm{pH} 8.3,50 \mathrm{mM} \mathrm{KCl}, 1.5 \mathrm{mM} \mathrm{MgCl}_{2}\right)$ and $9.0 \mathrm{ng}$ DNA template. Amplifications were performed using a PE 9700 thermal controller (Applied Biosystems, USA) with the following conditions: one cycle of $95^{\circ} \mathrm{C}$ for $7 \mathrm{~min}, 35$ cycles of $95^{\circ} \mathrm{C}$ for $1 \mathrm{~min}, 48-59^{\circ} \mathrm{C}$ for $1 \mathrm{~min}$ (according to each locus), and $72^{\circ} \mathrm{C}$ for $1 \mathrm{~min}$, and one cycle of $72^{\circ} \mathrm{C}$ for $20 \mathrm{~min}$ of final extension. Reaction conditions for some primers were optimized using the touchdown cycling program as described by Russello et al. (2001). The amplified products were diluted in a 1:2 multiplex as following: AgGT72 (6-FAM) and AgGT21 (HEX); AgGT83 (HEX) and AgGT12 (NED), and AgGT29 (HEX) and AgGT07 (NED). One microliter of the diluted reaction was added to 0.25 $\mu \mathrm{L}$ of DNA ladder standard (GeneScan 500 internal lane standard, ROX, Applied Biosystems), $0.45 \mu \mathrm{L}$ loading buffer ( $25 \mathrm{mM}$ EDTA and $50 \mathrm{mg} / \mathrm{mL}$ Blue-Dextran) and $2.3 \mu \mathrm{L}$ deionized formamide. Afterwards, the products were separated on 5\% denaturing polyacrylamide gels in a DNA automated sequencer (ABI Prism 377, Applied Biosystems). Fragments were automatically sized using the Genescan and Genotyper 2.1 softwares (Applied Biosystems).

\section{Genetic structure}

Microsatellite loci were characterized for the number of alleles per locus and population, the allelic richness for population, and for observed and expected heterozygosities $\left(\mathrm{H}_{\mathrm{E}}\right)$ under Hardy-Weinberg equilibrium (Nei, 1978). Genetic structure was accessed by Wright's (1951) statistics: $f, \theta$ and $\mathrm{F}$, obtained from an analysis of variance of allele frequencies (Cockerham, 1969). As most mutations in microsatellites involve the addition or subtraction of a small number of repeat units, according to a stepwise mutation model (Ota and Kimura, 1973; Valdes et al., 1993; Slatkin, 1995), population genetic differentiation was also estimated by $R_{\mathrm{ST}}$ (Slatkin, 1995). $R_{\mathrm{ST}}$ is obtained by analysis of variance of allele size and may be interpreted as the correlation between allele sizes of different individuals in the same population (Goodman, 1997). This is analogous to $\theta$, with the exception that for $\theta$ the correlation between allele frequencies of different individuals in the same population considers an infinite allele model (Cockerham, 1969; Weir and Cockerham, 1984). Analyses were performed using the FSTATS 2.9.3.2 software (Goudet, 2002). Statistical significance tests were based on 10,000 randomizations followed by sequential Bonferroni's correction (Goudet et al., 1996).

\section{Bottleneck}

To verify if populations were affected by size reduction leading to a bottleneck, we determined the heterozygosity excess by the Wilcoxon sign rank test using the Bottleneck software (Cornuet and Luikart, 1996). The bottleneck process may cause a faster loss of heterozygosity under mutation-drift equilibrium than loss of heterozygosity under Hardy-Weinberg equilibrium. Hence, populations that have experienced recent reduction in effective population size may present higher allele diversity $\left(\mathrm{H}_{\mathrm{E}}\right.$ under Hardy-Weinberg equilibrium) than $\mathrm{H}_{\mathrm{E}}$ under mutation-drift equilibrium $\mathrm{H}_{\mathrm{E}}$ for a given number of alleles in the population (Cornuet and Luikart, 1996; Luikart et al., 1998a,b). The distribution of $\mathrm{H}_{\mathrm{E}}$ under mutation-driff equilibrium for each locus and population was obtained by a simulation of a coalescent process. Because microsatellite loci may evolve following the stepwise mutation model (SMM; Ota and Kimura, 1973) or the two-phase mutation model (TPM; Di Rienzo et al., 1994), we per- 
formed the bottleneck test using 100\% SMM and combining the two models of mutation, with 70\% SMM and 30\% TPM (Luikart et al., 1998b).

\section{RESULTS}

All microsatellite loci showed no deviation from Hardy-Weinberg equilibrium (Table 2) resulting in nonsignificant $f$ values ( $\mathrm{P}>0.00833$, adjusted nominal level $5 \%$ with Bonferroni's correction, $\left.\mathrm{p}_{\mathrm{BC}}=0.00833\right)$ and all pairs of loci were in linkage equilibrium $\left(\mathrm{P}>0.00333, \mathrm{p}_{\mathrm{BC}}=\right.$ 0.00333 ). They displayed high levels of polymorphism, with the least variable (AgGT72) and the most variable (AgGT21 and AgGT83) loci with 15 and 23 alleles, respectively. They also presented high level of observed heterozygosity, from 0.808 up to 0.972 (Table 2).

\section{Table 2. Characterization of six microsatellite loci based on 74 Amazona aestiva.}

\begin{tabular}{lccccc}
\hline Locus & $\mathrm{N}$ & $A$ & $\mathrm{H}_{\mathrm{E}}$ & $\mathrm{H}_{\mathrm{O}}$ & $f$ \\
\hline AgGT07 $^{1}$ & 73 & 18 & 0.817 & 0.808 & 0.012 \\
AgGT12 $^{1}$ & 70 & 20 & 0.932 & 0.900 & 0.035 \\
AgGT21 $^{1}$ & 72 & 23 & 0.922 & 0.819 & 0.113 \\
AgGT29 $^{2}$ & 74 & 17 & 0.857 & 0.876 & 0.055 \\
AgGT72 $^{2}$ & 73 & 23 & 0.919 & 0.972 & 0.046 \\
AgGT83 & 72 & 19.3 & 0.936 & 0.864 & 0.038 \\
Overall loci $^{1}$ & & 0.897 &
\end{tabular}

All loci are in Hardy-Weinberg equilibrium $(\mathrm{P}>0.00833)$ and all pairs of loci are in linkage equilibrium $(\mathrm{P}>$ 0.00333). ${ }^{1}$ Russello et al. (2001); ${ }^{2}$ Russello et al. (2005). $\mathrm{N}=$ number of individuals; $A$ = total number of alleles; $\mathrm{H}_{\mathrm{E}}$ = expected heterozygosity; $\mathrm{H}_{\mathrm{O}}=$ observed heterozygosity; $f$ = inbreeding coefficient.

All populations showed no deviation from Hardy-Weinberg equilibrium (Table 3) resulting in nonsignificant $f$ values $\left(\mathrm{P}>0.00167, \mathrm{p}_{\mathrm{BC}}=0.0133\right)$ and suggesting random mating within populations. They also showed a high level of $\mathrm{H}_{\mathrm{E}}$, from 0.874 up to 0.895 (Table 3 ). The Minas Gerais (MG) population had the lower mean number of alleles per population while Mato Grosso do Sul (MS) showed the higher mean number (Table 3). The sampling effect could be discarded, since MG also had the lower allelic richness (Table 3).

Table 3. Characterization of five Amazona aestiva populations based on six microsatellite loci.

\begin{tabular}{llrrrrr}
\hline Locality & $\mathrm{N}$ & \multicolumn{1}{c}{$A$} & \multicolumn{1}{c}{$\mathrm{H}_{\mathrm{E}}$} & $\mathrm{H}_{\mathrm{O}}$ & \multicolumn{1}{c}{$f$} \\
\hline TO & 15 & 12.16 & 9.750 & 0.895 & 0.905 & -0.012 \\
DF & 11 & 10.83 & 10.030 & 0.888 & 0.826 & 0.052 \\
MG & 10 & 9.50 & 9.143 & 0.879 & 0.900 & -0.024 \\
MS & 24 & 14.33 & 9.592 & 0.874 & 0.811 & 0.091 \\
AR & 14 & 11.66 & 9.620 & 0.892 & 0.903 & -0.013 \\
Overall & 74 & 11.69 & 9.627 & 0.886 & 0.869 & 0.018 \\
\hline
\end{tabular}

$f$ values were not significant for all populations analyzed $(\mathrm{P}>0.00167) . \mathrm{N}=$ sample size; $A=$ mean number of alleles; $R s=$ allelic richness; $\mathrm{H}_{\mathrm{E}}=$ expected heterozygosity; $\mathrm{H}_{\mathrm{O}}=$ observed heterozygosity; $f$ = inbreeding coefficient. See Table 1 for locality abbreviations. 
A low but significant genetic differentiation among populations $\left(P>0.01040, \mathrm{p}_{\mathrm{BC}}\right.$ $=0.00100$; Table 4 ) was found. Pairwise $\theta$ was significant only for the most geographically distant populations, Argentina (AR) and Tocantins (TO) $\left(\mathrm{P}=0.005, \mathrm{p}_{\mathrm{BC}}=0.005\right.$; Table 5), suggesting that the significance of $\theta$ over all populations may be a bias caused by the differentiation between these two populations. In fact, $R_{\mathrm{ST}}$ was not significantly different from zero $\left(R_{\mathrm{ST}}=0.007\right.$; Table 4$)$, also suggesting that significant differentiation for $\theta$ may be a bias. Additionally, $\mathrm{F}$ and $f\left(\mathrm{P}>0.0010, \mathrm{p}_{\mathrm{BC}}=0.0043 ; \mathrm{P}>0.0019, \mathrm{p}_{\mathrm{BC}}=0.0317\right.$, respectively; Table 4) were also not significant, suggesting that mating pattern may not play an important role in population differentiation.

Table 4. Population genetic structure of Amazona aestiva based on an analysis of variance of allele frequencies and of allele size.

\begin{tabular}{lcccc}
\hline Locus & $f$ & $\theta$ & $\mathrm{F}$ & $R_{\text {ST }}$ \\
\hline AgGT07 $^{1}$ & 0.012 & 0.033 & 0.019 & 0.047 \\
AgGT12 $^{1}$ & 0.035 & 0.002 & 0.035 & -0.009 \\
AgGT21 $^{1}$ & 0.113 & -0.003 & 0.112 & -0.007 \\
AgGT29 $^{2}$ & 0.055 & 0.034 & 0.061 & -0.011 \\
AgGT72 $^{2}$ & 0.046 & 0.007 & 0.048 & 0.022 \\
AgGT83 $^{1}$ & -0.038 & 0.005 & -0.037 & 0.000 \\
Overall loci $^{-0.037}$ & $0.012^{*}$ & 0.040 & 0.007 \\
\hline
\end{tabular}

${ }^{1}$ Russello et al. (2001); ${ }^{2}$ Russello et al. (2005). $f=$ inbreeding coefficient; $\theta=$ fixation index (significant for value followed by asterisk); $\mathrm{F}=$ total inbreeding coefficient; $R_{\mathrm{ST}}=$ population genetic differentiation based on allele size.

Table 5. Values of $\theta$ for pairwise localities of Amazona aestiva based on six microsatellite loci.
\begin{tabular}{lcccc}
\hline Locality & AR & MS & DF & MG \\
\hline MS & 0.007 & & & \\
DF & 0.020 & 0.010 & 0.010 & 0.029 \\
MG & 0.023 & 0.021 & 0.011 & 0.001 \\
TO & $0.007^{*}$ & 0.011 & \\
\hline
\end{tabular}

$* \mathrm{P}=0.005$. See Table 1 for locality abbreviations.

No evidence of recent reduction in population size could be detected for both, strictly SMM $(\mathrm{P}>0.422)$ and $70 \%$ SMM and 30\% TPM $(\mathrm{P}>0.039$, assuming a significant level of 0.01$)$. Allele frequency distribution showed the L-shape expected by the mutation-drift equilibrium, with most alleles with low frequency and few alleles with high frequency (results not shown).

\section{DISCUSSION}

For the six microsatellite loci used in this study, the levels of polymorphism and of $\mathrm{H}_{\mathrm{E}}$ for A. aestiva (19.3 alleles per locus and $\mathrm{H}_{\mathrm{E}}=0.897$; Table 2) were higher than those observed for other parrots. For some threatened and endemic species, such as the red-spectacled parrot (Amazona pretrei; Caparroz et al., 2007), the red-tailed parrot (Amazona brasiliensis; Caparroz et al., 2007) and the St. Vincent parrot (Amazona guildingii; Russello et al., 2001, 2005), the mean number of alleles per locus (9.5, 7.5 and 4.2, respectively) was lower than the value found for A. aestiva as well as the 
values of $\mathrm{H}_{\mathrm{E}}(0.800,0.676$ and 0.548 , respectively). Even though $A$. aestiva is non-threatened and widely distributed, other species with the same characteristics show lower levels of polymorphism, such as the African grey parrot (Psittacus erithacus; Taylor and Parkin, 2007), which has shown 7.3 alleles per locus and $\mathrm{H}_{\mathrm{E}}=0.745$ for 11 microsatellite markers. These results indicate that $A$. aestiva still maintains high levels of genetic diversity, despite the intense anthropic pressures on its natural populations.

Our results show a low genetic differentiation among populations (Table 4). Although $\theta$ may underestimate genetic differentiation, $R_{\mathrm{ST}}$ was lower than $\theta$, showing that there is no divergence between identity by descendent and identity by state in the loci analyzed. Additionally, pairwise comparison showed significant differentiation only between the most distant populations AR and TO (Table 5), localized in the limits (southwest and northeast) of the sample sites, and $f$ was not significant for overall population or for each population (Tables 3 and 4), suggesting random mating within populations. These results suggest a clinal distribution of genetic variability, as observed for variation in plumage color of the two subspecies of $A$. aestiva. The primary difference between them is the coloration of the shoulder, which changes from red in eastern populations ( $A$. a. aestiva) to yellow in western populations ( $A$. a. xanthopteryx), with an intermediate phenotype with mixed red and yellow shoulder in the center of the distribution (Darrieu, 1983). We hypothesize that long distance dispersal may be responsible for this result, since the blue-fronted Amazon can fly long distances (Seixas and Mourão, 2000). The low differentiation for bird populations has already been described in other bird species that can potentially fly long distances, such as other Amazons (e.g., A. auropalliata; Wright et al., 2005), macaws (e.g., A. ararauna; Caparroz R, Miyaki CY and Baker AJ, unpublished data) and passerines (Dougall-Shackleton and Dougall-Shackleton, 2001).

Alternatively, the clinal distribution with differentiation between AR and TO populations, at the extreme of the geographic distribution, may also be explained by population-level phenomena such as introgression. Some subspecies of the $A$. ochrocephala complex and $A$. aestiva comprise a paraphyletic group (Eberhard and Bermingham, 2004; Russello and Amato, 2004; Ribas et al., 2007). Ribas and collaborators (2007) showed that there are two different mitochondrial lineages: one composed of $A$. a. aestiva individuals (middle-north region of the geographic distribution), including some individuals from MG (CG in Ribas et al., 2007) and A. o. xantholaema from Marajó Island, northeastern Brazil; the other composed of $A$. a. aestiva, including some individuals from MS (MI in Ribas et al., 2007), A. a. xanthopteryx (both from west-southwest region of the geographic distribution), A. o. nattereri and A. o. ochrocephala from Northwestern Brazil. We hypothesize that these two mitochondrial lineages hybridize in an area that coincides with the region where no significant genetic differentiation was detected (MS, Distrito Federal (DF) and MG populations) with microsatellite markers, which may be a contact region (hybridization zone) among these lineages (Figure 1). Moreover, in Pantanal Sul Mato-Grossense (MS), the blue-fronted Amazon has a mixed shoulder (yellow and red) (Darrieu 1983), morphological evidence that supports the hybridization of these two lineages.

Based on our results, it is not possible to decide which of these hypotheses is more likely, because we did not have enough $A$. ochrocephala samples to perform a population study with microsatellite markers. Thus, a detailed study, including more populations from the overlapping between $A$. aestiva and $A$. ochrocephala subspecies and populations from all $A$. ochrocephala subspecies, should be performed to better understand the evolution and taxonomic relationship of this group. 


\section{Implications for conservation}

The rapid and intense destruction and fragmentation of natural habitats due to the fast increase in human activities have progressively destroyed the natural habitat of $A$. aestiva, contributing effectively to the reduction of wild populations (Bucher and Martella, 1988; Collar and Juniper, 1992). Additionally, the capture of wild individuals for the pet trade has seriously affected the wild population of these species. These threats may interfere directly in the spatial distribution and in population size of the blue-fronted Amazon in the medium and long term. Nevertheless, the results obtained in this study suggest that these threats still have not had a strong impact on the genetic structure and diversity of the blue-fronted Amazon populations. However, A. aestiva has a long life expectancy (almost 70 years - data from captive individuals; Sick, 1997), and fragmentation in the core area of the geographic distribution of this species is a recent event (less than 60 years), considering the life cycle of this species. Possibly, some individuals that are still breeding may be older than the first anthropic disturbances. Thus, the effects of these impacts may have not yet affected the genetic structure and diversity of this species. Furthermore, with a long life expectancy, it is possible that the current population of $A$. aestiva is composed mainly of old individuals, and when these old individuals die, the populations will suffer a sudden, drastic size reduction, which may cause a reduction in genetic variability. In fact, the mortality of nestlings due to predation and cavity loss as a result of habitat loss is very high and may lead to a very low recruitment rate, reinforced by the illegal capture of nestlings for the pet trade (Seixas and Mourão, 2002; Resende FO and Caparroz R, unpublished data). Other studies showed that eggs and offspring of A. aestiva are intensely captured in the natural populations (Pinho and Nogueira, 2000; Seixas and Mourão, 2000; Longatto and Seixas, 2004; Banchs and Moschione, 2006), which may interfere directly in the recruitment rate.

We suggest that conservation strategies for $A$. aestiva should consider the evidence of clinal distribution of allele frequency and morphological differentiation in shoulder color. Thus, for the management and conservation of the species, the populations from Argentina and Tocantins should be considered as different management units, and the other populations from the center of the geographical distribution as another management unit. Independent of the taxonomic relationship between $A$. aestiva and A. ochrocephala complex (see discussion above), it is important to maintain the different genetic and morphological populations described in this paper.

\section{ACKNOWLEDGMENTS}

We would like to thank all students from the Molecular Ecology and Conservation Genetics Group at the Universidade Católica de Brasília for their kind help in the field and laboratory work, and the staff at the National Park of Grande Sertão Veredas, Jardim Botânico de Brasília, Reserva Ecólogica do IBGE and Estação Ecológica de Águas Emendadas for their help during the fieldwork. We greatly appreciate the support of Cristina Y. Miyaki and the staff at the Jardim Zoológico de Brasília that contributed with some blood samples. We also thank anonymous reviewers for helpful suggestions and comments on a previous version of this paper. Research supported by Conselho Nacional de Desenvolvimento Científico e Tecnológico (CNPq). 


\section{REFERENCES}

Banchs RA and Moschione FN (2006). Para la conservación y el aprovechamiento sustentable del loro hablador (Amazona aestiva) en la Argentina. In: Manejo de Fauna Silvestre en la Argentina. Programas de uso Sustentable (Bolkovic ML and Ramadori D, eds.). Dirección de Fauna Silvestre. Secretaría de Ambiente y Desarrollo Sustentable, Buenos Aires, 15-25.

Beissinger SR and Bucher EH (1992). Sustainable harvesting of parrots for conservation. In: New World Parrots in Crisis: Solutions from Conservation Biology (Beissinger SR and Snyder NER, eds.). Smithsonian Institution Press, Washington, 73-115.

Bruford M, Hanotte O, Brookfield JFY and Burke T (1992). Single locus and multilocus DNA fingerprinting. In: Molecular Genetic Analysis of Populations: A Practical Approach (Hoelzel AR, ed.). Oxford University Press, New York, 225269.

Bucher EH and Martella MB (1988). Preliminary report on the current status of Amazona aestiva in the Western Chaco. ICBO Parrotletter 1: 9-10.

Caparroz R, Leite KCE, Chinalia LA, Myiaki CY, et al. (2007). Characterization of microsatellite loci in three species of Amazona (Psittaciformes) using heterologous primers. Ornitol. Neotrop. 18: 439-444.

Cockerham C (1969). Variance of gene frequencies. Evolution 23: 72-84.

Collar NJ (1997). Family Psittacidae (Parrots). In: Handbook of the Birds of the World (del Hoyo J, Elliot A and Sargatal J, eds.). Lynx Edicions, Barcelona, 280-477.

Collar NJ and Juniper AT (1992). Dimensions and Causes of the Parrot Conservation Crisis. In: New World Parrots in Crisis: Solutions from Conservation Biology (Beissinger SR and Snyder NR, eds.). Smithsonian Institution Press, Washington, 1-24.

Cornuet JM and Luikart G (1996). Description and power analysis of two tests for detecting recent population bottlenecks from allele frequency data. Genetics 144: 2001-2014.

Coulon A, Guillot G, Cosson JF, Angibault JM, et al. (2006). Genetic structure is influenced by landscape features: empirical evidence from a roe deer population. Mol. Ecol. 15: 1669-1679.

Darrieu CA (1983). Revision de las razas geograficas de Amazona aestiva (Linne) (Aves, Psittacidae). Neutropica 29: 3-10.

Dethmers KE, Broderick D, Moritz C, Fitzsimmons NN, et al. (2006). The genetic structure of Australasian green turtles (Chelonia mydas): exploring the geographical scale of genetic exchange. Mol. Ecol. 15: 3931-3946.

Di Rienzo A, Peterson AC, Garza JC, Valdes AM, et al. (1994). Mutational processes of simple-sequence repeat loci in human populations. Proc. Natl. Acad. Sci. U. S. A. 91:3166-3170.

Dougall-Shackleton EA and Dougall-Shackleton SA (2001). Cultural and genetic evolution in mountain white-crowned sparrows: song dialects are associated with population structure. Evolution 55: 2568-2575.

Eberhard JR and Bermingham E (2004). Phylogeny and biogeography of the Amazona ochrocephala (Aves: Psittacidae) complex. Auk 121: 318-332.

Eizirik E, Kim JH, Menotti-Raymond M, Crawshaw PG Jr, et al. (2001). Phylogeography, population history and conservation genetics of jaguars (Panthera onca, Mammalia, Felidae). Mol. Ecol. 10: 65-79.

Fernandez-Juricic E, Martella MB and Alvarez EV (1998). Vocalizations of the blue-fronted Amazon (Amazona aestiva) in the Chancaní Reserve, Córdoba, Argentina. Wilson Bull. 110: 352-361.

Frankham R (1995). Conservation genetics. Annu. Rev. Genet. 29: 305-327.

Frankham R, Ballou JD and Briscoe DA (2002). Introduction to Conservation Genetics. Cambridge University Press, New York.

Franklin IR (1980). Evolutionary Change in Small Populations. In: Conservation Biology: An Evolutionary-Ecological Perspective (Soulé ME and Wilcox BA, eds.). Sinauer Associates, Sunderland, 135-150.

Gilpin ME (1987). Spatial Structure and Population Vulnerability. In: Viable Populations for Conservation (Soulé ME, ed.). Cambridge University Press, Cambridge, 125-139.

Gilpin ME and Soulé ME (1986). Minimum Viable Populations: Processes of Species Extinction. In: Conservation Biology: The Science of Scarcity and Diversity (Soulé ME, ed.). Sinauer Associates, Sunderland, 19-34.

Goodman SJ (1997). Rst Calc: a collection of computer programs for calculating estimates of genetic differentiation from microsatellite data and determining their significance. Mol. Ecol. 6: 881-885.

Goudet J (2002). FSTAT: a program to estimate and test gene diversities and fixation indices. Available at http://www. unil.ch/izea/softwares/fstat.html.

Goudet J, Raymond M, de Meeus T and Rousset F (1996). Testing differentiation in diploid populations. Genetics 144: 1933-1940. 
Longatto JA and Seixas GHF (2004). Enforcement techniques of wild trafficking in Mato Grosso do Sul. Nat. Conserv. 2: 101-109.

Luikart G, Sherwin WB, Steele BM and Allendorf FW (1998a). Usefulness of molecular markers for detecting population bottlenecks via monitoring genetic change. Mol. Ecol. 7: 963-974.

Luikart G, Allendorf FW, Cornuet JM and Sherwin WB (1998b). Distortion of allele frequency distributions provides a test for recent population bottlenecks. J. Hered. 89: 238-247.

Moritz C (1994). Applications of mitochondrial DNA in conservation: a critical review. Mol. Ecol. 3: 401-411.

Nei M (1978). Estimation of average heterozygosity and genetic distance from a small number of individuals. Genetics 89: 583-590.

Ota T and Kimura M (1973). A model of mutation appropriate to estimate the number of electrophoretically detectable alleles in a finite population. Genet. Res. 22: 201-204.

Paetkau D (1999). Using genetic to identify intraspecific conservation units: a critique of current proposals. Conserv. Biol. 13: 1507-1509.

Paetkau D, Amstrup SC, Born EW, Calvert W, et al. (1999). Genetic structure of the world's polar bear populations. Mol. Ecol. 8: 1571-1584.

Pinho JB and Nogueira FMB (2000). Mostra da retirada de psitacídeos em cativeiro na cidade de Cuiabá e Pantanal de Poconé, Mato Grosso, no período 1995-1997. Ararajuba 8: 51-53.

Ribas CC, Tavares ES, Yoshihara C and Miyaki CY (2007). Phylogeny and biogeography of yellow-headed and bluefronted parrots (Amazona ochrocephala and Amazona aestiva) with special reference to the South American taxa. IBIS 149: 564-574.

Russello M, Calcagnotto D, DeSalle R and Amato G (2001). Characterisation of microsatellite loci in the endangered St. Vincent Parrot, Amazona guildingii. Mol. Ecol. Notes 1: 162-164.

Russello M, Lin K, Caccone A and Amato G (2005). Additional microsatellite loci for the endangered St. Vincent parrot, Amazona guildingii. Conserv. Genet. 6: 643-645.

Russello MA and Amato G (2004). A molecular phylogeny of Amazona: implications for Neotropical parrot biogeography, taxonomy, and conservation. Mol. Phylogenet. Evol. 30: 421-437.

Ryder OA (1986). Species conservation and systematics: the dilemma of subspecies. Trends Ecol. Evol. 1: 9-10.

Seixas GHF and Mourão GM (2000). Assessment of restocking blue-fronted Amazon (Amazona aestiva) in the Pantanal of Brazil. Ararajuba 8: 73-78.

Seixas GHF and Mourão GM (2002). Nesting success and hatching survival of the blue-fronted Amazon (Amazona aestiva) in the Pantanal of Mato Grosso do Sul, Brazil. J. Field Ornithol. 73: 399-409.

Seixas GHF and Mourão GM (2003). Growth of nestlings of the blue-fronted Amazon (Amazona aestiva) raised in the wild or in captivity. Ornitol. Neotrop. 14: 295-305.

Sick H (1997). Ornitologia Brasileira, uma Introdução. Editora Nova Fronteira, Rio de Janeiro.

Slatkin M (1995). A measure of population subdivision based on microsatellite allele frequencies. Genetics 139: $457-$ 462.

Soulé ME (1987). Viable Populations for Conservation. Cambridge University Press, New York.

Taylor TD and Parkin DT (2007). Characterization of 12 microsatellite primer pairs for the African grey parrot, Psittacus erithacus and their conservation across the Psittaciformes. Mol. Ecol. Notes 7: 163-167.

Valdes AM, Slatkin M and Freimer NB (1993). Allele frequencies at microsatellite loci: the stepwise mutation model revisited. Genetics 133: 737-749.

Wayne RK (1992). On the use of molecular genetic characters to investigate species status. Conserv. Biol. 6: 590-592.

Weir BS and Cockerham CC (1984). Estimating F-statistics for the analysis of population structure. Evolution 38: 13581370.

Wright S (1943). Isolation by distance. Genetics 28: 114-138.

Wright S (1951). The genetical structure of populations. Ann. Eugenics 15: 323-354.

Wright TF, Rodriguez AM and Fleischer RC (2005). Vocal dialects, sex-biased dispersal, and microsatellite population structure in the parrot Amazona auropalliata. Mol. Ecol. 14: 1197-1205. 